\title{
Whom do dying patients tell?
}

\author{
JOHN HINTON
}

\section{Summary and conclusions}

Eighty married patients dying of cancer were assessed for their overt awareness of their condition. Of the 62 who discussed the possibility of dying, 22 had spoken of this to hospital staff, 43 to their husband or wife, and 53 to the interviewer. Those more certain of dying were more likely to speak about it. Patients previously considered "nervous" people more often showed their awareness, but current anxiety had no consistent effect. More overt sharing of awareness tended to happen in marriages considered average or poor by the spouse than in some closer marital partnerships. The patients' communication of awareness to wife or husband was consistently better when the spouse favoured telling the patient. Patients also tended to disclose their awareness of dying more frequently to those staff prepared to discuss the matter. The findings have implications for the care of the dying.

\section{Introduction}

Recent writings on the care of dying people report that many are aware that their illness may be fatal. ${ }^{2} 2$ A leading question may disclose an awareness not mentioned spontaneously. ${ }^{3}$ Nevertheless some people treating people with mortal disease find that patients rarely talk to them of dying. Similarly relatives often assert that a patient is unaware of approaching death. If we believe that the recognition of a patient's awareness of dying affects our approach to his care it is pertinent to discover to what extent people recognise they are dying, whom they are likely to tell, and why.

\section{Patients and methods}

Eighty married people with fatal neoplastic disease were assessed for their awareness of dying. The assessments were made at a mean of 10 weeks (range $1-50$ weeks) before death. The 50 female and 30 male patients were aged from 24 to 80 (mean 58); 74 were Christian, mostly Protestant. They were selected as being able and willing to converse easily, and any physical discomfort had been made tolerable by treatment. Their diagnoses were cancers of breast (20), ovary and uterus (12), bowel (10), lung (9), prostate and bladder (6), other tissues (19), and Hodgkin's disease (4). The patients were receiving a high standard of care in four different settings-either a radiotherapy unit in an acute hospital, a home for cancer patients, a hospice inpatient unit, or at home with the hospice outpatient service. The

\footnotetext{
Academic Department of Psychiatry, Middlesex Hospital Medical School, London W1P 8AA

JOHN HINTON, MD, FRCP, professor of psychiatry
}

comparison of these units has been published. ${ }^{4}$ The hospice had a clear policy that patients should be given ample opportunity to discuss frankly their illness and its customs.

I interviewed the patients at the bedside or in a room near the ward or outpatient clinic. They were encouraged to talk freely and often discussed their prognosis spontaneously. Only indirect conversational leads regarding the future outlook were given, and the topic was not pursued if there was no response. The patients' words on their awareness of dying were rated on a linear scale, with 1-4 indicating varying expectations towards recovery, 5 non-committal, and 6-9 varying expectations of dying from possibility to certainty. The spouses were then interviewed and similar ratings made on the basis of what the patient had said to them. Lastly, a senior nurse or doctor who knew the patient well made their assessments from what the patient had told the staff.

Other assessments of the patient's psychological state were made at the same time-for instance, current anxiety. During the interview with the spouse information was sought on certain personality traits such as general nervousness versus stability and also the spouse's estimate of how close the marital relationship had been (all ratings from 1 to 9). Towards the end of the conversation the spouse was asked to express an opinion on telling the patient about his condition. The data have been evaluated in $2 \times 2$ tables using Fisher's exact test as a two-tail test. For $3 \times 2$ tables, probability has been assessed by $\chi^{2}$ tests where most cells have a value greater than 5 . Where a trend was predicted, the $\chi^{2}$ test for trend was used.

\section{Results}

Of the 80 patients, 11 told the interviewer that they were certainly dying, 27 spoke of dying as probable or possible, and a further 15 mentioned the chance of a fatal outcome. Thus $53(66 \%)$ said they recognised they might or would soon die, while six $(8 \%)$ were noncommittal and $21(26 \%)$ spoke only of improvement. Some patients spoke to either their spouse or the staff of dying and not to me, but they tended to say less to their spouse than to me and less still to the staff caring for them. The figure illustrates this selective tendency. Of the 80 patients, 62 had spoken of dying to someone at this stage; 15 had shown their awareness to all; while most told some but not others. Factors that might influence the variation in communication by the 62 aware patients are now considered.

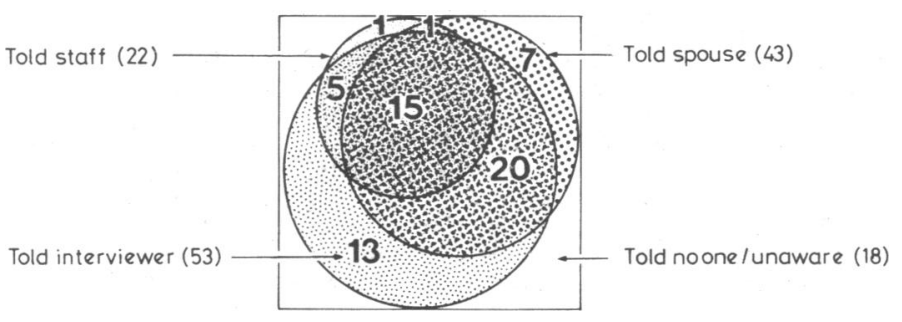

Awareness of possibly dying as shown to different people by 80 patients with terminal cancer. The square represents the 80 patients and the three shaded circles their communicated awareness to staff, spouse, and interviewer. 


\section{ASPECTS OF THE PATIENT AND COMMUNICATION}

The sex of the patient made no statistically significant difference to the proportion who showed their awareness to the staff (men $32 \%$, women $38 \%$ ) or to their spouse (men $64 \%$, women $72 \%$ ). Age made a little difference in that younger patients were less likely to state their awareness to the staff; three of the $20(15 \%)$ under 55 compared with 19 of the $42(45 \%)$ older patients $(p<0.05)$. This association with age was insignificant for communication with the spouse, $65 \%$ of those under 55 telling compared with $71 \%$ aged over 55 . The time before death that these assessments were made had no statistically significant effect on the proportion of people showing awareness. It should be noted that this comparison was of many individuals assessed only once at different times before death and not people reassessed at progressive stages in their dying.

The patients' degree of certainty that they were dying influenced their frankness. All of those sure they were dying told their spouse. With decreasing certainty, as rated by their own comments, the proportion dropped from $100 \%$ (rating 9 , that is, certain of dying) to $80 \%$ (rating 8 ) to $61 \%$ (rating 7 ) to $33 \%$ (rating 6 , that is, chance of dying) $(p<0.001)$. The trend was similar in their communication with staff, saying more to them when sure; the proportions decreased from $63 \%$ (certain) to $50 \%$ (probable) to $22 \%$ (possible) to only $7 \%$ in those who just recognised a chance that they could be dying $(p<0.001)$

The patients' current anxiety had no consistent effect on their speaking of dying to the spouse. Of the patients rated as anxious, 39\% told the staff compared with $29 \%$ of those with only slight or no anxiety, but this had no statistical significance. Even when communication was considered in relation to a narrower aspect of anxietythe patients' concern over the outcome of their illness-there was still no statistically significant finding. Of greater influence was the patient's sociability or withdrawal which had been rated; $50 \%$ of the more sociable confided their awareness to the staff, $39 \%$ of the average, and $12 \%$ of those becoming withdrawn $(\mathrm{p}<0.05)$. This general sociability did not appear to affect the patient's likelihood of speaking of dying to the spouse.

The patients' previous personality influenced what they said. In contrast to current anxiety the spouses' description of the patient as previously being an anxious or nervous individual was clearly associated with freer communication of awareness. Of the 24 so assessed, 22 $(92 \%)$ told the spouse of their awareness compared with 21 of the 38 $(55 \%)$ rated as average or noticeably stable people $(\mathrm{p}<0.01)$. Communication to the staff followed a similar pattern although the difference was less significant, only $18 \%$ of the 22 patients judged very stable spoke to the staff of dying compared with $45 \%$ of the others $(\mathrm{p}<0.06)$

\section{RELATIONSHIPS AND COMMUNICATION}

The duration of the relationship could, in theory, facilitate communication, but in fact knowing a person for a longer time did not of itself increase the likelihood of the patients speaking of their awareness. Of these 62 patients, $69 \%$ spoke of dying to their spouse whom they had known longest, $35 \%$ to the staff whom they had known for some little while, but $85 \%$ to an interviewer they had never met before. This suggested that the nature of the relationship had more effect than its duration. The influence of certain qualities of relationships or attitudes which had been assessed in this study was therefore evaluated by comparing groups of patients with different qualities in their marriage and by comparing different policies held by otherwise similar staff groups.

The closeness of the marital relationship was associated with some differences in the patients' readiness to communicate their awareness to the spouse. When the spouse described the marital relationship as "very good" 11 of the 15 patients $(73 \%)$ spoke to their wife or husband of dying. When the marital relationship was considered "good" 20 of the $34(59 \%)$ showed some awareness. But with average or poor marriages as many as 12 of the $13(92 \%)$ told their spouse $(p<0 \cdot 1)$ If this lower level of statistical significance is acceptable the result indicates that a distant marital affection or even disharmony tended to facilitate talking about dying. In moderately harmonious marriages open communication of awareness was least frequent. A very close relationship reversed the trend to reticence and eased the patient's disclosure. This complex picture within marriage, where frank talking was not directly proportional to affection, accorded with the patients pattern of speaking with staff. Their candour to the staff about dying did not increase simply according to how much they liked them. When asked about their relationship with staff the patients usually answered in terms of warm approval. Of the patients who gave the highest possible praise, $34 \%$ had spoken to the staff about dying compared with $39 \%$ of those patients who expressed moderate approval or less satisfaction with nurses and doctors; clearly these proportions were very similar.

A more specific aspect of the relationship considered was the potential recipients' attitude to listening to another person openly admit he may be dying. Patients in the hospice, with its declared policy of allowing the dying to speak freely about their condition if they wished, were compared with those in the two other units where staff varied in frankness and more often encouraged an optimism for recovery. Of the 32 hospice patients, $14(44 \%)$ showed their awareness to staff compared with eight of the $30(27 \%)$ patients in the other units. In this case the tendency of patients to speak more freely to those more willing to hear did not reach statistical significance. If, however, it is considered valid to include the interviewer, who wanted the patients to speak frankly, the trend becomes clear. Of the aware patients, $85 \%$ told the interviewer, $44 \%$ told the more frankly communicating staff, and $27 \%$ spoke to the staff with the less free communication policy $(\mathrm{p}<0.001)$.

This trend was more clearly established between patient and spouse. When asked their views on telling the patient about his condition many spouses favoured reticence. The patients volunteered their own awareness to only 18 of the $32(56 \%)$ spouses who believed the painful truth should remain unspoken, to 13 of the $18(72 \%)$ who gave a qualified answer, and to all $(100 \%)$ of the 12 spouses who favoured telling the truth to the dying $(\mathrm{p}<0.01)$.

\section{Discussion}

At least three-quarters of these patients with terminal cancer were aware of the possibility of dying, which accords with some previous reports. In 1962 Hackett and Weisman ${ }^{5}$ found that 20 dying patients came, in psychotherapy, to confide their recognition that death was approaching. In 1969 Kubler-Ross ${ }^{1}$ reported that in interviews with over 200 patients dying in hospital only three maintained denial to the end. This degree of awareness surprised many, but even with less intense interviews many dying people volunteered their awareness. A 1963 report from a London hospital ${ }^{6}$ showed that over $75 \%$ spoke of some awareness of dying before the end. A subsequent inquiry by Cartwright et $a l^{7}$ into a random sample of all deaths in England and Wales in 1969 found that relatives considered $37 \%$ of the dying knew for certain and another $20 \%$ half-knew.

The discrepancies between such reports and a common clinical impression that only a few dying patients know may be partly due to circumstances-different diseases, individuals, social settings, and cultures. The present study highlights the feature that patients often know but do not tell the staff. Many patients with cancer would like greater opportunity to "discuss their situation more fully," but not always with their doctor. ${ }^{8}$ What factors affect this selective communication by patients ?

Their immediate psychological state to some extent influenced the information these patients volunteered. The more certain they were of dying, the more likely they were to say so. Uncertainty has many roots. Patients do not have the medical knowledge of the staff. Even the staff themselves could not foretell with complete accuracy-in this study of 80 patients a further seven had been assessed as dying but were excluded when they survived one year. Many patients waver in their expectation of dying. Their uncertainty and concern about death may vary with their discomfort, optimism increasing if symptoms improve. ${ }^{9}$ Awareness of dying also varies as people seek refuge from emotional pain by denial. Denial is rarely complete or consistent; Hacket and Weisman ${ }^{5}$ used the term "middle knowledge" for the paradoxical state of repudiating death while realising that one is dying. Uncertainty stemming from these logical and emotional causes makes patients less likely to speak openly of dying, and their insight is easily underestimated.

Current anxiety had no consistent effect on these patients' readiness to talk about dying. This was slightly unexpected as most people working in terminal care units have stark memories of trying to comfort troubled patients temporarily overwhelmed by fears of dying. Nevertheless, statistically, the anxious utterances were balanced by the matter-of-fact comments of 
calm people talking of their death. Equally, both the tranquil and the frightened could hide their awareness. Habitual nervous traits had a different influence from immediate anxiety. Those patients considered by the spouse to be normally rather nervous showed their awareness more often, whereas those judged stable were economical with talk of dying. Such data hold ambiguities; they may imply that the strong are silent, or that habitual reticence is rightly or wrongly assumed to indicate stability. Clearly, terms such as "nervous" or "stable" are ill-defined; they were chosen because relatives could readily use these words about patients and so provide information easily available to any clinician.

Knowing a patient for a longer time did not necessarily facilitate communication about dying. That $36 \%$ of these dying patients with some awareness had shown it to staff treating them while $85 \%$ told a hitherto unknown investigator invites explanation. Perhaps patients choose their words according to which of their needs their audience can meet. Very ill people depend so much on the staff and may well hesitate to admit to an expectation of dying. It might imply ingratitude over failure to cure, it might mean a source of optimism would dry up, especially in the young; or it might even lead to the partial rejection of the dying. Someone not responsible for the patients' care can be used to meet a different need, to share doubts over the unpleasant truth. Another explanation lies in the timing of the initial meeting. A new visitor may be told the latest state of awareness, whereas those met earlier in the illness may have the prior optimistic attitude maintained in their exchanges. Other aspects of relationships with patients will affect communication; in this study it would be misleading to ignore that my acquaintance with the problems of dying people and my psychiatric training might influence the mutual exchange of conversational cues.

People's attitudes affect what they are told. Comparing different views on communicating with patients about their condition gave an indication that when staff were prepared for franker discussion they were told more. There is evidence that nursing staff, for instance, may have sympathy and a sound overall recognition of patients' worries but still fail to discover the particular concerns of an individual. ${ }^{10}$ Communication may be hindered at different stages. Patients may not attempt to communicate, they may be inefficient in conveying their message, and their indirect attempts to communicate may be distorted or lost. Receivers may misinterpret or fail to hear. Glaser and Strauss ${ }^{11}$ laid emphasis on the competition for truth between the dying patient versus the rest. In the "closed awareness" context the staff and relative guard against the dying patient discovering the truth by attempting to sustain the fiction that recovery is expected. Such manoeuvres were described by some patients in this current study, rarely those in the hospice. The "closed suspicion" context, where the staff does not recognise the patient's suspicion, appeared more often than Glaser and Strauss indicated. "Mutual pretence" and "open awareness" were also common; the overall impression was that collaboration between patients and staff prevailed over constraint in these selected units. Some staff had a very open attitude sustained by their experience which contradicted the fear that frankness was an irretrievable step to distress.

The influence of a franker attitude to the dying was shown clearly in the communication of awareness between patient and spouse. The spouse's attitude had a more consistent effect on increasing the numbers of patients speaking of dying than did marital affection. Both partners spoke of the close ties that could facilitate exchange but also increased the underlying distress. When the partners had not been very close the trend was towards franker speaking. Affection aroused a protective attitude, either people attempting to shield the dying or the dying sustaining the others. In the closest marriages communication about dying began to prevail over protective denial; this complex process warrants further inquiry.

Clinicians should recognise, therefore, that many more patients dying of cancer are aware than tell the staff. Patients considered stable are particularly reticent while the more nervous continue to share their worries when facing death. Patients who are less sure of dying are more likely to keep their doubts from staff. Moreover, people's own attitude towards talking of death affects what patients disclose. In general these patients preferred it when they could speak frankly with the staff and were happier when this was so. ${ }^{4}$ This does not imply that all patients benefit from full display of the painful truth as soon as the possibility enters their heads; but some patients wish to discuss it and find it difficult to do so. Recent evidence indicates that policies are changing towards greater frankness with patients with cancer, ${ }^{12}$ although in the same report the doctors thought that research was unlikely to alter their own practice. It is understandable that general findings may seem to have limited application when speaking with an individual of his own death. These 80 dying people did indicate that given someone prepared to listen they, as individuals, would often share their awareness and could be helped.

I am grateful to the patients who in their final illness so readily helped and made this study possible, together with the wives, husbands, and staff; I also thank Brian Newman for statistical advice.

\section{References}

1 Kubler-Ross E. On death and dying. New York: Macmillan, 1969.

2 Parkes CM. Psychological aspects. In: Saunders CM, ed. The management of terminal disease. London: E Arnold, 1978:44-64.

3 Witzel L. Behaviour of the dying patient. Br Med F 1975;ii :81-2.

${ }^{4}$ Hinton J. Comparison of places and policies for terminal care. Lancet $1979 ; \mathrm{i}: 29-32$

${ }^{5}$ Hackett TP, Weisman AD. The treatment of the dying. In: Masserman $\mathrm{JH}$, ed. Current psychiatric therapies 2. New York: Grune and Stratton, 1962:121-6.

${ }^{6}$ Hinton JM. The physical and mental distress of the dying. $O F$ Med 1963; 32:1-21.

${ }^{7}$ Cartwright A, Hockey L, Anderson JL. Life before death. London: Routledge and Kegan Paul, 1973.

${ }^{8}$ Mitchell GW, Glicksman AS. Cancer patients: knowledge and attitudes. Cancer 1977;40:61-71.

${ }^{9}$ Davies RK, Quinlan DM, McKegney FP, et al. Organic factors and psychological adjustment in advanced cancer patients. Psychosom Med $1973 ; 35: 464-71$.

10 Johnston M. Communication of patients' feelings in hospital. In: Bennett $\mathrm{AE}$, ed. Communication between doctors and patients. Oxford: Oxford University Press, 1976: 29-43.

11 Glaser BG, Strauss AL. Awareness of dying. Chicago: Aldine Publishing Company, 1965.

12 Novack DH, Plumer R, Smith RL, et al. Changes in physicians' attitudes toward telling the cancer patient. $\mathcal{F} A M A 1979 ; 241: 897-900$.

(Accepted 24 September 1980) (Ace

$=$

Assessing the tissue turgor over the sternum and forehead is an important clinical sign of dehydration. Is there a definite physiological change in the elderly?

Tissue turgor in the elderly is not easy to assess because of the lack of elasticity in an old person's skin. It is widely recognised that to try to assess the turgor of the skin over the limbs is unreliable. On the other hand, the skin over the masseter, temple, and sternum are all reasonably reliable, dehydration being shown by a delayed recoil of the skin after deformation. My own experience does not suggest that in the elderly the forehead is as good as these other sites. Even in well-hydrated old people the recoil of the skin of the forehead appears to be delayed. No clinical estimate of dehydration is entirely reliable, and a recently published article ${ }^{1}$ advocates the use of a dehydration score. The items rated include a dry tongue, lax skin, temporary postural fall in systolic blood pressure, an altered packed cell volume, blood urea concentration, and serum osmolarity. A weight increase of more than $1.5 \mathrm{~kg}$ in a week in the absence of oedema is also a retrospective sign of dehydration.

${ }^{1}$ Seymour DF, Henscke PJ, Cape RDT, Campbell AJ. Acute confusional states and dementia in the elderly: the role of dehydration/volume depletion, physical and dementia in the elderly: the role of dehydrat
illness and age. Age and Ageing 1980;9:137-46. 